\title{
ANALISIS AGROINDUSTRI NENAS UD BERKAT BERSAMA DI DESA KUALU NENAS KECAMATAN TAMBANG KABUPATEN KAMPAR
}

\author{
Mufti, Rini Nizar, Niken Nurwati \\ Jln. Yos Sudarso Km. 8 Rumbai Pekanbaru \\ mufti@yahoo.com
}

\begin{abstract}
ABSTRAK
Nenas (Ananas comosus L) merupakan tanaman buah yang berasal dari Brazil. Nenas selain dapat dimakan secara langsung dapat diolah lebih lanjut menjadi keripik nenas, dodol nenas, selai, sirop dan lainnya. Di Desa Kualu Nenas terdapat agroindustri yang berbahan baku nenas yaitu keripik nenas, wajik nenas dan dodol nenas. Keripik nenas merupakan produk olahan yang paling banyak dikembangkan oleh pengrajin pengolahan nenas di Desa Kualu Nenas. Pengolahan hasil pertanian atau agroindustri merupakan subsistem agribisnis yang sangat besar peranannya dalam meningkatkan nilai tambah dari hasil pertanian

Pengusaha juga akan berusaha melakukan usaha dengan layak agar mendapatkan pendapatan yang maksimal untuk meningkatkan kesejahteraannya. Berkaitan dengan kondisi ini maka penelitian ini bertujuan untuk melakukan analisis kelayakan usaha, Break Even Poin (BEP), dan nilai tambah yang mampu dihasilkan oleh industri nenas. Hasil penelitian menunjukkan bahwa Agroindustri nenas "Berkat Bersama Usaha pada bulan Mei 2016 menghasilkan produk keripik nenas sebesar $651 \mathrm{Kg}$. dengan biaya produksi yang dikeluarkan Rp. Sebesar 45.475.122,- dan pendapatan bersih yang diperoleh sebesar Rp. 13.114.878,-. Hasil Analisis BEP menunjukkan bahwa usaha ini dalam kondisi impas bila memproduksi keripik nenas $60 \mathrm{Kg}$ dengan penerimaan sebesar Rp. 5.371.598,-Jika diharapkan laba Rp. 20.000.000,-, maka penjualan kripik harus mencapai 902 Kg. Nilai tambah yang dihasilkan oleh usaha "Berkat Bersama" adalah sebesar Rp. 872,- dari per kilogram nenas segar.
\end{abstract}

Keywords: Usaha nenas, Analisis usaha, Nilai tambah 


\begin{abstract}
Pineapple (Ananas comosus L) is a fruit crop coming from Brazil. Besides pineapple can be eaten directly can be further processed into chips pineapple, pineapple dodol, jam, syrup and others. In the village there Nenas Kualu agroindustrial raw material, namely pineapple pineapple chips, diamonds pineapple and pineapple dodol. Pineapple chips are most widely refined products developed by craftsmen in the village Kualu pineapple processing pineapple. Processing of agricultural or agro-industry is a subsystem of agribusiness very big role in increasing the added value of agricultural products.

Employers will also seek to do business with a decent order to obtain the maximum revenue to improve their welfare. In connection with this condition, this study aims to conduct feasibility analysis, Break Even Point (BEP), and the added value that can be produced by the pineapple industry. The results showed that the Agro-Industry Pineapple "Thanks to the Joint Enterprises in May 2016 to produce pineapple chips of $651 \mathrm{Kg}$. With a production cost of Rp. A sum of $45,475,122$, - and the revenue generated Rp. 13,114,878, -. Results BEP analysis shows that this business in the breaks even when producing pineapple chips $60 \mathrm{~kg}$ with admission of Rp. 5,371,598, -. If the expected profit of Rp. 20.000.000, -, sales of chips should reach $902 \mathrm{Kg}$. the added value generated by effort "Berkat Bersama" is Rp. 872, - /kg of fresh pineapple.
\end{abstract}

Keywords: Business pineapples, business analysis, value-added

\section{Pendahuluan}

Nenas (Ananas comosus L) merupakan tanaman buah yang dapat dimakan secara langsung dapat diolah lebih lanjut menjadi keripik nenas, dodol nenas, selai, sirop dan lainnya. Penghasil terbesar nenas di Provinsi Riau ada di Kabupaten Kampar, Khususnya di Kecamatan Tambang, yaitu ada Di Desa Kualu Nenas dan Desa Rimbo Panjang. Desa Kualu Nenas terdapat agroindustri yang berbahan baku nenas yaitu keripik nenas, wajik nenas dan dodol nenas. Keripik nenas merupakan produk olahan yang paling banyak dikembangkan oleh pengrajin pengolahan nenas di Desa Kualu Nenas. Umumnya merupakan industri rumah tangga dan padat karya, sehingga jumlah pengusaha pengolahan nenas yang berada di daerah ini dapat mempengaruhi juga pada penyerapan tenaga kerja, selain itu pengusaha juga akan berusaha 
melakukan usaha dengan layak agar mendapatkan pendapatan yang maksimal untuk meningkatkan kesejahteraannya. Berkaitan dengan kondisi ini maka penelitian ini bertujuan untuk melakukan analisis kelayakan usaha, Break Even Poin (BEP), dan nilai tambah yang mampu dihasilkan oleh industri nenas. Diharapkan hasil penelitian ini dapat memberikan masukan untuk pengembangan agroindustri nenas di Kabupaten Kampar khususnya di Desa Kualu Nenas.

\section{Metode Penelitian}

\section{Tempat dan Waktu Penelitian}

Metode yang dipergunakan dalam penelitian ini adalah metode survey. Penelitian dilaksanakan di Desa Kulau Nenas Kecamatan Tambang Kabupaten Kampar . Pemilihan lokasi penelitian ini atas dasar pertimbangan bahwa pada Desa ini merupakan sentra produksi keripik nenas. Waktu penelitian selama kurang lebih dua bulan, yaitu dari bulan Maret sampai dengan April 2016.

\section{Teknik Pengambilan Sampel}

Penarikan sampel dilakukan secara purposive terhadap satu produsen kripik nenas "BERKAT BERSAMA" Dengan pertimbangan bahwa agroindustri "BERKAT BERSAMA" yang paling besar skala usahanya ( Jumlah tenaga kerja 6 orang, bahan baku nenas 200 buah /hari)

\section{Teknik Pengumpulan Data}

Data yang dikumpulkan dalam penelitian ini meliputi data primer dan data sekunder. Data primer diperoleh dari responden dengan menggunakan daftar pertanyaan (Questioner) dan pengamatan langsung di lapangan.

\section{Analisis Data}

Untuk menghitung biaya penyusutan alat digunakan rumus menurut Hernanto ( 1989 )

$$
\mathrm{D}=\frac{\mathbf{N b}-\mathbf{N s}}{\mathbf{N}}
$$


Dimana :

$\mathrm{D}=$ Depretion $/$ penyusutan $(\mathrm{Rp}$ proses produksi )

$\mathrm{Nb}=$ Nilai baru $(\mathrm{Rp} /$ unit $)$

Ns $=$ Nilai sisa $(\mathrm{Rp} /$ unit $)$

$\mathrm{N}=$ Umur ekonomis (tahun )

Untuk meghitung penerimaan bersih agroindustri nenas digunakan rumus menurut Sukartawati (1987) sebagai berikut :

$$
\begin{aligned}
& \Pi=\mathrm{TR}-\mathrm{TC} \\
& \Pi=\mathrm{y} . \mathrm{PY}-\mathrm{X} . \mathrm{Px}
\end{aligned}
$$

Dimana :

$\Pi=$ Pendapatan bersih usaha agroindustri nenas ( $\mathrm{Rp} /$ proses produksi)

$\mathrm{Y}=$ Jumlah produksi nenas $(\mathrm{Kg} /$ Proses produksi )

Py $=$ Harga produksi nenas ( $\mathrm{Rp} / \mathrm{Kg}$ )

$\mathrm{X}=$ Faktor produksi yang digunakan ( $\mathrm{Kg} /$ proses produksi )

Tambahan penjualan $=\frac{\text { Target laba }}{\text { KTO }}=\frac{\text { Target laba }}{\mathrm{HU}-\mathrm{BV}}$

Dimana :

$\mathrm{KTO}=$ Kontribusi terhadap overhead

$\mathrm{HU}=$ Harga jual produk

$\mathrm{BV}=$ Biaya variable/ unit produk

Untuk melakukan analisis nilai tambah metode Hayami.
Px $=$ Harga Faktor produksi yang digunakan ( $\mathrm{Rp} / \mathrm{Kg}$ )

Untuk menghitung BEP digunakan rumus menurut Yacob, $2009: 158$.

$$
\mathrm{BEP}_{(\mathrm{Q})}=\frac{\mathrm{a}}{(\mathrm{p}-\mathrm{b})}
$$

$$
\mathrm{BEP}_{(\mathrm{Rp})}=\frac{\mathrm{a}}{(1-\mathrm{b} / \mathrm{p})}
$$

\section{Keterangan :}

$$
\mathrm{a} \quad=\text { Fixed Cost }
$$

$\mathrm{b} \quad=$ Biaya variabel per unit

$\mathrm{p} \quad=$ Harga per unit

$\mathrm{q}=$ Jumlah produksi

Untuk melakukan analisis volume-laba digunakan rumus menurut Downey W. David dan Erickson Steven P (1992) sbb:

\section{HASIL PENELITIAN DAN}

PEMBAHASAN

Keadaan Umum Daerah Penelitian 


\begin{abstract}
Desa Kualau Nenas merupakan salah satu desa di Kecamatan Tambang Kabupaten Kampar, dengan ketinggian 40 meter dari permukaan laut, bertopografi dataran. Desa Kualu Nenas letaknya sangatn strategis perbatasan dengan ibu kota Propinsi Riau, 27 Km jalan lintas Sumatra Barat.
\end{abstract}

Mata Pencaharian penduduk Desa Kualau Nenas sangat bervariasi, pada sektor pertanian 1385 orang; PNS 98 orang; Dagang 159 orang; TNI/POLRI 12 orang; Pegawai swasta 326 orang Pensiunan 18 orang; wiraswasta 874 0rang. ( Monografi Desa Kualau Nenas Tahun 2012)

\section{Gambaran Umum Agroindustri Nenas "Berkat Bersama"}

Agroindustri nenas "Berkat Bersama" milik Pak Muslimin terletak di Desa Kualau Nenas Kecamatan Tambang Kabupaten Kampar. Bentuk badan usaha adalah perusahaan perorangan. Agroindustri nenas "Berkat Bersama" berdiri tahun 2001 sebagai usaha pengolahan nenas skala rumah tangga. Agroindustri nenas milik bapak Muslimin pada awal berdirinya mendapat binaan dan bantuan dari Univeresitas Riau dan BPTP ( Balai Penyuluh Tekonologi Pertanian) Propinsi Riau.Selanjutnya dengan adanya kredit dari Bank, bapak Muslimin membeli vacuum frying, menyewa tempat. Agroindustri nenas "Berkat Bersama" sekarang sudah memiliki kios penjualan,tempat pengolahan lengkap drengan peralatannya.

Proses Pembuatan Kripik Nenas "Berkat Bersama" 
Proses pengolahan buah nenas menjadi kripik nenas disajikan dalam gambar $1 \mathrm{sbb}$ :

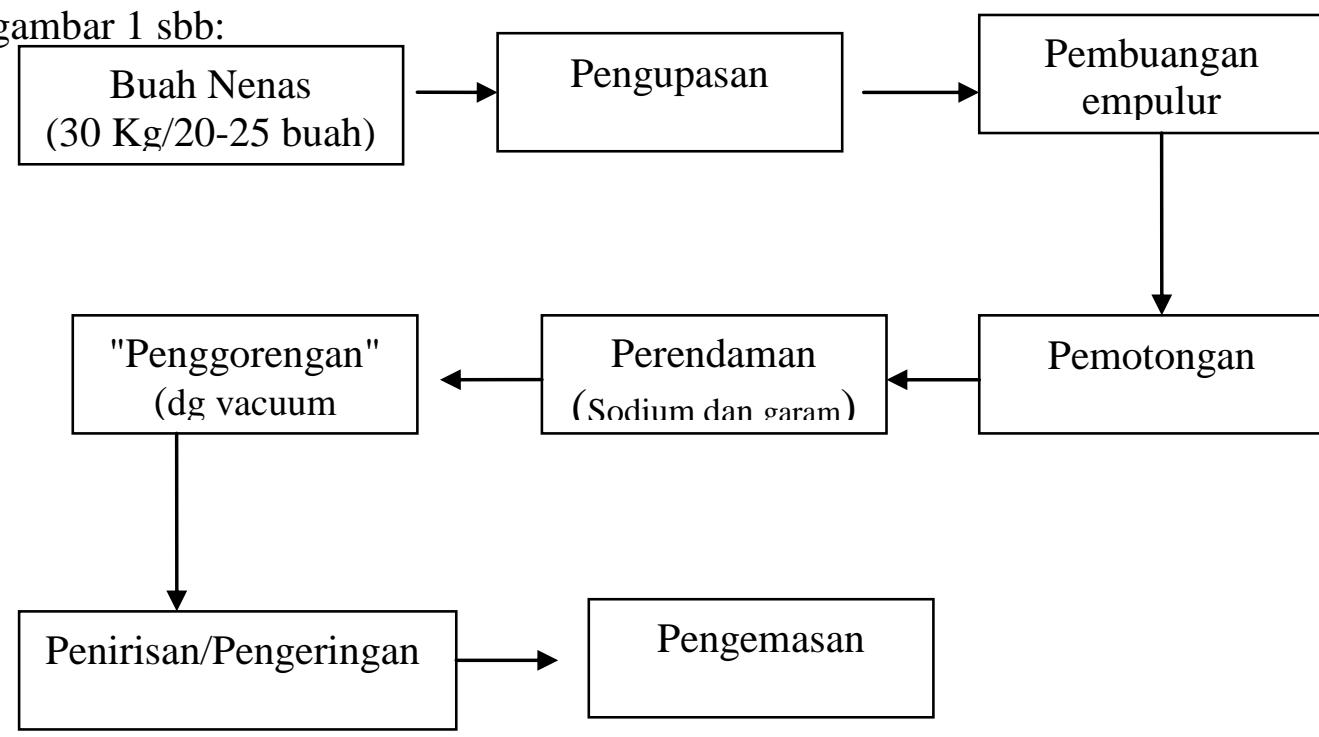

Gambar 1. Proses pengolahan Kripik Nenas "Berkat Bersama"

Bahan baku nenas diperoleh dari kebun bapak Muslimin sendiri seluas 2 Ha. Jika bahan baku dari kebun seindiri tidak mencukupi maka pak Muslimin membeli nenas dari petani nenas yang ada di sekitarnya.Untuk satu kali penggorangan dibutuhkan bahan baku nenas sebanyak $30 \mathrm{Kg}$ atau sekitar 20-22 buah nenas ukuran besar.

Nenas dikupas untuk membuang kulitnya. Pengupasan kulit agak tebal supaya mata nenas terbuang. Kemudian dibuang empulurnya, dan selanjutnya dilakukan pemotongan. Proses pemotongan dilakukan secara manual. Menurutt bapak Muslimin proses pemotongan tidak bisa dilakukan dengan mesin karena belum dijumpai mesin yag dapat digunakan untuk memotong buah nenas karena sifat buah yang agak lunak, sehingga jika pemotongan dilakukan dengan mesin dikawatirkan hasil potongan akan rusak. Tahap selanjutnya, buah nenas yang sudah dipotong direndam dalam larutan sodium dan garam selama 15 menit dengan tujuan untuk menghilangan caiaran gatal dari buah nenas. Proses selanjutnya adalah 
"penggorengan", penirisan untuk memisahkan sisa minyak gorengen dari proses "penggorengan" dan pengemasan.

\section{Analisis Usaha Agroindustri Nenas}

\section{"Berkat Bersam"}

\section{Biaya Proses Produksi}

Biaya produksi merupakan biaya yang dibutuhkan dalam kegiatan agrondustri nenas "Berkat Bersama" biaya dipisah menurut biaya tetap dan biaya tidak tetap. Total biaya agroindustri nenas merupakan jumlah dari biaya tetap dan biaya tidak tetap. Total biaya agroindustri nenas "Berkat Bersama" selama bulan Mei disajikan pada tabel 1 .

kegiatan proses produksi. Pada

Tabel 1. Total Biaya Agroindustri Nenas "Berkat Bersama" Dalam Bulan Mei Tahun 2016

\begin{tabular}{|l|l|r|r|r|r|}
\hline No & \multicolumn{1}{|c|}{ Uraian } & Jmh & $\begin{array}{c}\text { Harga } \\
(\mathrm{Rp} / \text { Unit })\end{array}$ & Biaya (Rp) & $\begin{array}{c}\text { Prosentase } \\
(\%)\end{array}$ \\
\hline 1. & Biaya Tetap (Rp/bl) & & & 1.323 .750 & 2,91 \\
\hline 2. & - Bahan Baku & & & & \\
& Buah Nenas Segar (buah) & 4.340 & 4.000 & 17.360 .000 & 38,17 \\
& - Bahan Penunjang : & & & & \\
& Minyak goreng (Kg) & 282,4 & 11.400 & 3.219 .246 & 7,08 \\
& Garam (Kg) & 19,34 & 3.000 & 58.026 & 0,13 \\
& Sodium (Kg) & 10,85 & 6.000 & 65.100 & 0,14 \\
& Gas (Kg) & 188 & 6.000 & 1.128 .000 & 2,48 \\
& Plastik kemasan (Kg) & 54,25 & 56.000 & 3.038 .000 & 6,68 \\
& Kotak Kemasan (buah) & 6.510 & 1.700 & 11.067 .000 & 24,34 \\
& Listrik & & & 3.200 .000 & 7,04 \\
& Bensin( L) & 80 & 6.450 & 516.000 & 1,13 \\
\hline 3 & Tenaga Kerja (HKP) & 89,80 & & 4.500 .000 & 9,90 \\
\hline & \multicolumn{2}{|c}{ Jumlah } & & 45.475 .122 & 100,00 \\
\hline
\end{tabular}

Berdasarkan tabel 1. dapat dibahas bahwa prosentase paling tinggi dalam agroindustri nenas adalah biaya bahan baku $(38,17 \%)$, kotak kemasan 24,34\% tenaga kerja 9,90\%, minyak goreng 7,08\%, plastik 7,04\%. Pada pembahasan ini perlu mendapatkan perhatian ternyata kotak kemasan dan plastik secara keseluruhan mencapai $31,02 \%$ dari total biaya.

\section{Produksi dan Pendapatan}

Perhitungan biaya dan pendapatan agroindustri nenas "Berkat Bersama" 
selama bulan Mei tahun 2016 disajikan padsa tabel 2.

Tabel 2. Produksi dan Pendapatan Agroindustri nenas "berkat Bersama" bulan Mei Tahun 2016.

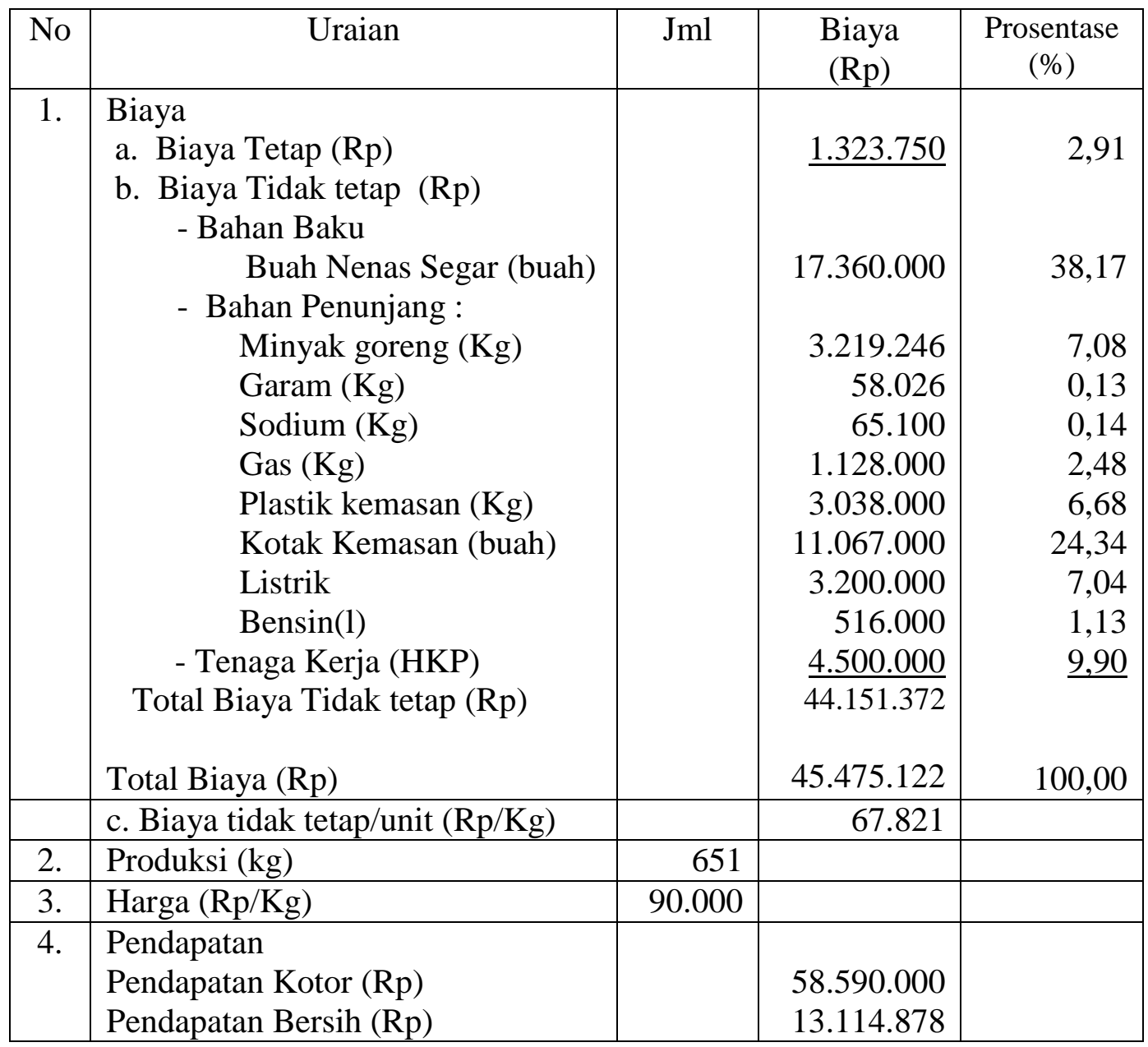

Pada tabel 2. dapat dibahas bahwa pendapatan bersih sebesar Rp. 13.114.878,-, diperoleh dengan total biaya sebesar Rp. 45.475.122,-. Jika kita perhatikan komposisi biaya proses produksi, komponen yang besar adalah pada biaya bahan baku $(38,17 \%)$ kemudian jumlah dari biaya plastik ditambah biaya kotak kemasan $(31,02 \%)$, tentu saja hal ini perlu diupayakan untuk dicari cara penghematan. Dalam dunia bisnis plastik dan kotak kemasan memang dapat menjadi daya tarik tersendiri disamping citarasa dari produknya. Tetapi prosentase yang tinggi pada 
plastik dan kotak kemasan ingin mendapatkan laba sebesar Rp. mengakibatkan turunnya pendapatan bersih.

Analisis BEP dan Volum20.000.000,- maka harus menambah penjualan $902 \mathrm{Kg}$ atau total penjualan menjadi $962 \mathrm{Kg}$.

Biaya memberikan hasil BEP ( Q) Analisis Nilai Tambah Metode sebesar $60 \mathrm{Kg}$, dan $\mathrm{BEP}(\mathrm{Rp})=\mathrm{Rp}$.

\section{Hayami}

\subsection{1 .598 ,- dan jika perusahaan}

Tabel 3. Hasil Analisis Nilai Tambah pada Usaha Keripik Nenas UD. Berkat Bersama Bulan Mei 2016

\begin{tabular}{|r|l|r|}
\hline No & Variabel & \multicolumn{1}{l|}{ Nilai } \\
\hline & Output, Input dan Harga & 651 \\
\hline 1 & Output (kg/bulan) & 6510 \\
\hline 2 & Bahan Baku (kg/bulan) & 89,80 \\
\hline 3 & Tenaga kerja (HKP/bulan) & 0,1 \\
\hline 4 & Faktor Konversi (1/2) & 0,01 \\
\hline 5 & Koefisien tenaga kerja (3/2) & 90.000 \\
\hline 6 & Harga output (Rp/kg) & 50.000 \\
\hline 7 & Upah rata-rata tenaga kerja (Rp/HOK) & \\
\hline & Pendapatan dan Keuntungan (Rp/kg bahan & $4.000,-$ \\
\hline 8 & baku) & $4.128,-$ \\
\hline 9 & Sumbangan input lain (Rp/kg nenas segar) & $9.000,-$ \\
\hline 10 & Nilai output (4 x 6) & $872,-$ \\
\hline $11 \mathrm{a}$ & Nilai tambah (10-9-8) & $9.69 \%$ \\
\hline b & Rasio nilai tambah (11a/10) x 100\%) & 500 \\
\hline 12 a & Imbalan tenaga kerja (5x7) & $57,34 \%$ \\
\hline b & Bagian tenaga kerja (12a/11a) x 100\%) & $372,-$ \\
\hline 13 a & Keuntungan (11 a - 12 a) & $42,66 \%$ \\
\hline b & Tingkat keuntungan (13a/11a) x 100\% & 5.000 \\
\hline & Balas Jasa Faktor Produksi & $10 \%$ \\
\hline 14 & Marjin (10-8) & $7,44 \%$ \\
\hline a & Pendapatan tenaga kerja & \\
\hline b & Sumbangan input lain & \\
\hline c & Keuntungan perusahaan & \\
\hline & & \\
\hline
\end{tabular}

Nilai output diperoleh dari hasil perkalian harga output per kilogram dengan factor konversi. Nilai output sebesar Rp. 9.000,- 
memberikan nilai tambah sebesar Rp. 872,- per kilogram atau sebesar 9, 69 persen, yang merupakan nilai tambah kotor karena masih belum memperhitungkan imbalan untuk tenaga kerja. Imbalan tenaga kerja sebesar Rp. 500,- atau sebesar 57,34 persen dari nilai tambah merupakan imbalan yang diterima oleh tenaga kerja.

Usaha keripik nenas ini memperoleh keuntungan sebesar Rp. 372,- per kilogram. Dengan tingkat keuntungan 42,66 persen yang artinya bahwa 42,66 persen dari nilai tambah merupakan keuntungan pengusaha, yang merupakan keuntungan bersih karena sudah mengeluarkan imbalan untuk tenaga kerja.

Margin dari pengolahan nenas segar menjadi keripik nenas adalah sebesar Rp. 5.000,-. Margin ini bila didistribusikan menjadi imbalan tenaga kerja, sumbangan input lain dan keuntungan pengusaha, berturut-turut adalah sebesar: $10 \%, 82,56 \%$ dan $7,44 \%$. Terlihat bagian untuk input lain paling besar biayanya

\section{KESIMPULAN DAN}

SARAN

\section{Kesimpulan}

1. Agroindustri nenas "Berkat Bersama Usaha pada bulan Mei 2016 menghasilkan produk keripik nenas sebesar $651 \mathrm{Kg}$. dengan biaya produksi yang dikeluarkan Rp. Sebesar 45.475.122,- dan pendapatan bersih yang diperoleh sebesar Rp. 13.114.878,-

2. Hasil Analisis BEP menunjukkan bahwa usaha ini dalam kondisi impas bila memproduksi keripik nenas $60 \mathrm{Kg}$ dengan penerimaan sebesar Rp. 5.371.598,- Jika diharapkan laba Rp. 20.000.000,-, maka penjualan kripik harus mencapai 902 $\mathrm{Kg}$.

3. Nilai tambah yang dihasilkan oleh usaha "Berkat Bersama" adalah sebesar Rp. 872,- dari per kilogram nenas segar.

\subsection{Saran}


Untuk mendapatkan

keuntungan yang lebih besar

hendaknya

Usaha

Agroindustri

dapat

menghemat pada pembiayaan

Bahan baku dan kemasan.

\section{DAFTAR PUSTAKA}

Hayami Y, Kawagoe T, Morooka Y, Siregar M. 1987. Agricultural Marketing and Processing in Upland Java. A Perspective from a Sunda Village. Bogor: The CPGRT Centre.

Hernanto F. 1988. Ilmu Usahatani. Penebar Swadaya. Jakarta
Ibrahim Y. 2009. Studi Kelayakan Bisnis. Penerbit Rineka Cipta.

Jakarta

Syarif Hidayat1, Marimin, Ani Suryani, Sukardi, Mohamad

Yani. 2012. Modifikasi Metode Hayami Untuk Perhitungan Nilai Tambah Rantai Pasok Agroindustri Kelapa Sawit. Jurnal eknologi Industri Pertanian 22.(1): 22-31 (2012)

Sukartawi. 2000. Analisis

Usahatani. Penenrbit UI-

Press. Jakarta

Widodo. 2003. Peran Agribisnis Usaha Kecil Dan Menengah Untuk Memperkokoh Ekonomi Nasional. Liberty.Yogyakarta. 